\title{
poesía de Milagros Terán
}

${ }^{1}$ Carlos Martínez Rivas

Recibido: 02 de septiembre de 2012 / Aceptado: 13 de diciembre de 2012

\section{Biografía}

Nació en León, Nicaragua.

Galardonada con el Premio Nacional de Poesía Mariana Sansón en 2007 por su libro Sol Lascivo (Anide: Hivos, 2007).

Es autora de los poemarios:

Las Luces en la Sien, (Managua: Vanguardia 1993) con prólogo de Gioconda Belli;

Plaza de los Comunes (Managua: CNE: Norad, 2002);

Sol Lascivo (Managua: ANIDE: Hivos, 2007) basado en su experiencia de vida en Zimbabwe, África.

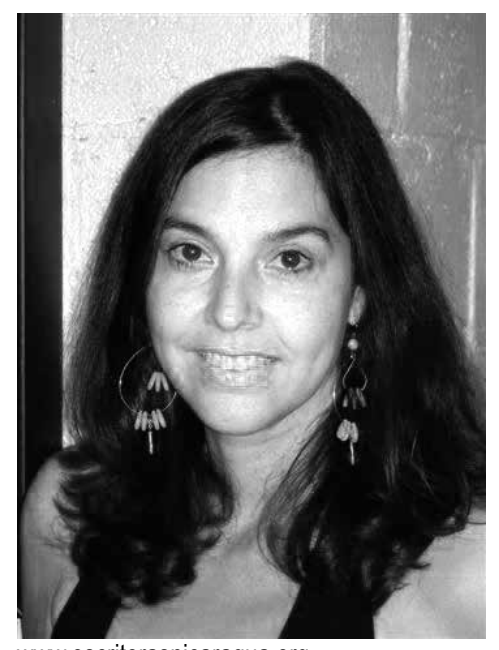

Poemas de una Niña (Managua: Fondo

Editorial Libros para Niños, 2010) es una recopilación de poemas escritos cuando niña, ilustrados.

Ha incursionado en la ficción, publicando en Puerto Rico: El Diario de Una Poeta (Revista Exégesis, Universidad de Puerto Rico, 1994), trabajo que recibió muy buena crítica.

Además de sus diplomas en Lengua Francesa y Relaciones Internacionales es Licenciada en Lenguas por la Universidad de George Mason, Virginia y es Máster en Literatura Latinoamericana de la Universidad de Maryland (1998), Estados Unidos.

Ha publicado y aparecido en diversas antologías en América del Norte, Centroamérica, América del Sur, Inglaterra, Italia, España, Francia, y en países del sudeste africano. Más recientemente en EEUU Al Pie de la Casa Blanca: Poetas Hispanos de Washington DC (New York: Academia Norteamericana de la Lengua 2010), y en México: Versos para el Recreo | Antología de Poemas para Niños | (Instituto Sinaloense de Cultura/ La Otra, 2011)

Sus poemas han sido traducidos y publicados en inglés, francés, italiano y portugués.

1 Poeta nicaragüense (q.e.p.d).

\section{RESUMEN}

La poesía de Milagros Terán, una de las poetas más importantes de Nicaragua, es presentada en Cultura de Paz.

La belleza de lo cotidiano en la trascendencia de la palabra poética. Carlos Martínez Rivas, extraordinario y singular poeta de nuestra lengua, escribe una carta valorando textos de Milagros Terán.

\section{ABSTRACT}

The Milagros Terán's poetry, one of the most important poets of Nicaragua, is presented in Culture of Peace Journal.

The beauty of everyday life in the transcendence of the poetic word. Carlos Martinez Rivas, an extraordinary and unique poet in our language, writes a letter in which makes an evaluation of Milagros Terán’s texts.

Key words: poetry, enigma, maternity, beautiful, love. 


\section{Carta de Carlos Martínez Rivas a Milagros Terán}

Domingo 17 de enero de 1993 11:00 a.m.

To: María Milagros Terán

7418 Colshire Drive

McLean, Virginia

USA

Querida amiga: aunque continúo en la incógnita de si vino Usted a Nicaragua; porque no creo, si así fuere que permanezca en León, escondida. Así que, vuelvo a escribirle. Hará, más de una semana y menos de quince días, le escribí, acusándole recibo de su presente 'Chrismático' (que aún aguarda ser abierto en la oscura esquina de una gaveta, en un closet). Acompañaba mi carta, una hoja, con unas líneas escritas a máquina: un reproche, y una estrofa de unos versos dodecasílabos consonantados.

En esa carta, deliberadamente, para dejar como único motivo mi incertidumbre y perplejidad con respecto a su anuncio de visita (el 19 de diciembre); la aparición misteriosa del 'paquetito', en mi patio; la posterior ausencia de noticia suya, y explicación a todo el enigma; con ese propósito, deliberadamente no quise referirme a sus dos bellos poemas: LAS MUECAS y ADIOS A SARAJEVO. Aunque ADIOS A SARAJEVO has beenhauntingme since ; y es muy impresionante, diría desgarrador; y el instante y la partida y todas las implicaciones dramáticas están trasmitidas en forma muy eficaz (además, ha seguido alimentándose, el poema, de las sucesivas noticias que me encuentro en los diarios); a pesar de todo ello, encuentro que LAS MUECAS, escrito cuatro meses antes, contiene una extraña síntesis de sujetos, temas, impresiones, atisbos, abstractos, que me dan una impresión; que me revelan, una sorprendente madurez literaria./ Es una suma, una adición de instantes y de instantáneas milagrosas. Es su primer poema de ruptura con todo lo suyo anterior, que yo conocí antes. Los que usted me mostraba, hace cerca de ocho años. Es, para hablar en términos pictóricos modernos, como si dijéramos: Picasso, pasando de las épocas azul, y rosa, a los primeros intentos del cubismo./

De su carta; y de sus expresiones de ¿amor? no sé que decirme a mí, menos, saber qué decirle a Usted. Su carta termina así: "Le quiero siempre igual, tal vez más." Pero, ¿cómo me quiere? A mí se me funde el corazón leyendo eso; y otras expresiones; ¡ay! ¿Cómo debo interpretarlas? Con su enigmática conducta de no hacerme, o haberme hecho saber si vino a Nicaragua. Si pudo verme, y no quiso hacerlo. Yo quería, deseaba, necesitaba hablar con Usted. Que nos viéramos: frente a frente ¿no? después de tantos años, y de tantas cosas.

Por ese anuncio del Nuevo Amanecer Cultural, que leí el viernes 15, busqué ayer sábado 16, el suplemento cultural. Viera Usted, el salto de mi corazón cuando vi allí anunciado el mágico nombre. Le envío ambos recortes. HYDE PARK, es delicioso y magistral en esa aparente sencillez de poesía "georgiana", "inglesa". Muy bien capta usted, and conveyit, la humedad, lo verde, el romanticismo de las puertas de hierro... Busqué entre mis Antologías de Poesía Inglesa, y tomos breves que tengo sobre los más jóvenes, impresos y editados por Harold Pinter, y no encontré a Brian Patten. ¿Podría, Usted, enviarme, copiados a máquina, algunos de sus poemas? - Cuando piense, usted, publicar su primer libro, permítame hacerle algunas reflexiones acerca de si aparecer sola, o presentada. Se lo digo, porque, cuando en 1974, Gioconda Belli iba a publicar su primer libro, "Sobre la Grama", yo le aconsejé no publicarlo con el prólogo que ella me dijo, entonces, que estaba escribiendo, para ella, José Coronel Urtecho. No me hizo caso. Y se arrepintió.

Carlos Martínez Rivas 


\section{Literatura}

\section{Poemas de Milagros Terán}

\section{NO QUIERO QUE ESTA GUERRA ME CAMBIE}

No quiero que se me acabe la alegría.

No quiero que esta guerra

me cambie,

que el peso de su rueda

me marque.

No quiero que el espejo

me devuelva en la mañana

su huella

en la comisura de mis labios.

Me resisto a esta metamorfosis,

A los años de consignas

proféticas

que calan hondo

dentro del corazón

y me entristecen.

Necesito oxígeno

para sembrar la bandera

en el campanario más alto.

Acariciar con el resto de hombres y mujeres -Prometeos-

el vientre del espacio.

Managua, 1986

(Las Luces en la Sien, 1993)

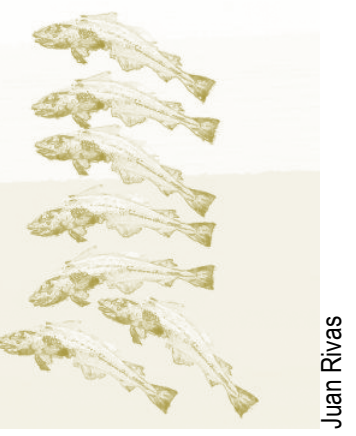

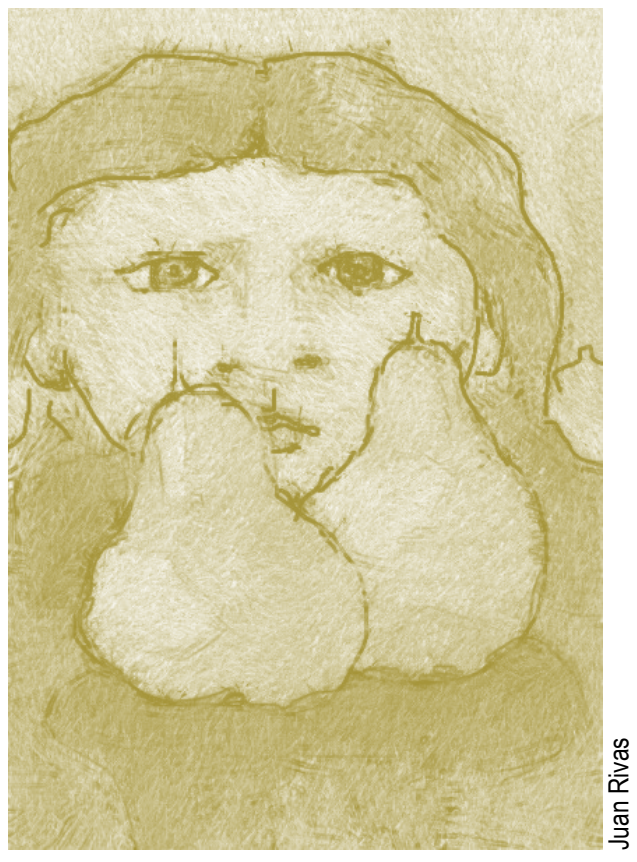

\section{TE DI MI CUERPO}

Te di mi cuerpo,

mis piernas de cristal lozano

paseándose por tus aposentos.

Te di mi cuerpo

solamente mi cuerpo;

el haz de luz del goce

los ojos de la perdición

la boca campana nerviosa

de los besos.

Mi cuerpo solamente.

Managua, 1987

(Las Luces en la Sien, 1993) 


\section{Literatura}

\section{LAS MUECAS}

El acomodo, el sueño, la puerta abierta.

La primera cana descubierta.

El mimo, el susurro del hombre,

el hambre, la sombra del adiós.

El gesto desabrido, la caricia torpe,

el sueño, el aburrimiento.

Tus ojos verdes mustios

sobre mi cuerpo lacerado.

El acomodo, el sueño,

la superficie tosca, la inclinación

tenue de la luz.

La culpa. El sonido del arrepentimiento.

La revisión interna. El verano triste,

tan triste y tan gris como el invierno.

Las aberraciones. El tambor de la espera,

el sueño, el aburimiento.

Los intentos salados como lágrimas,

las muecas, el adiós.

Washington DC, 1992

[Las Luces en la Sien, 1993]

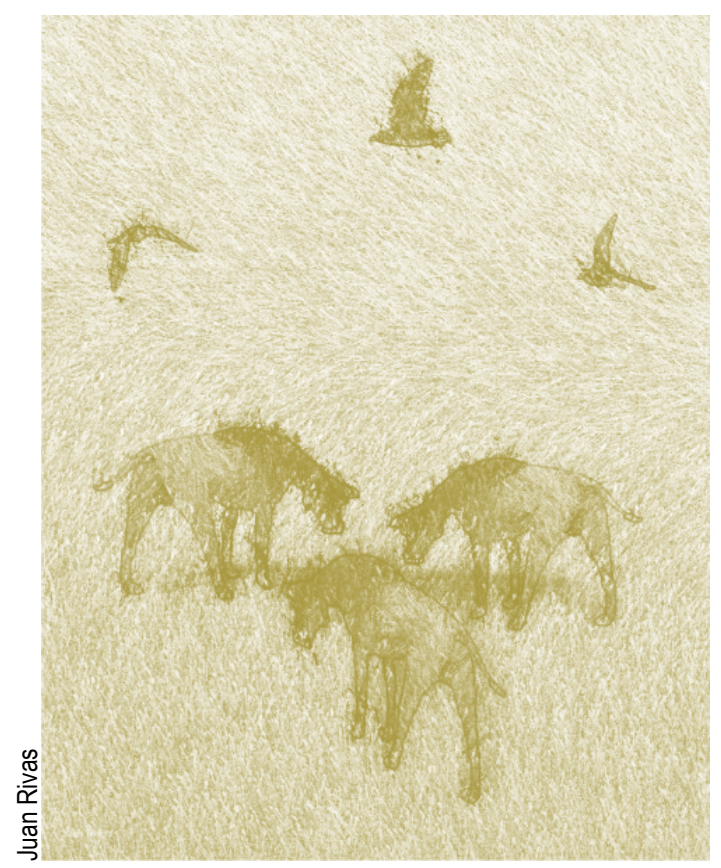

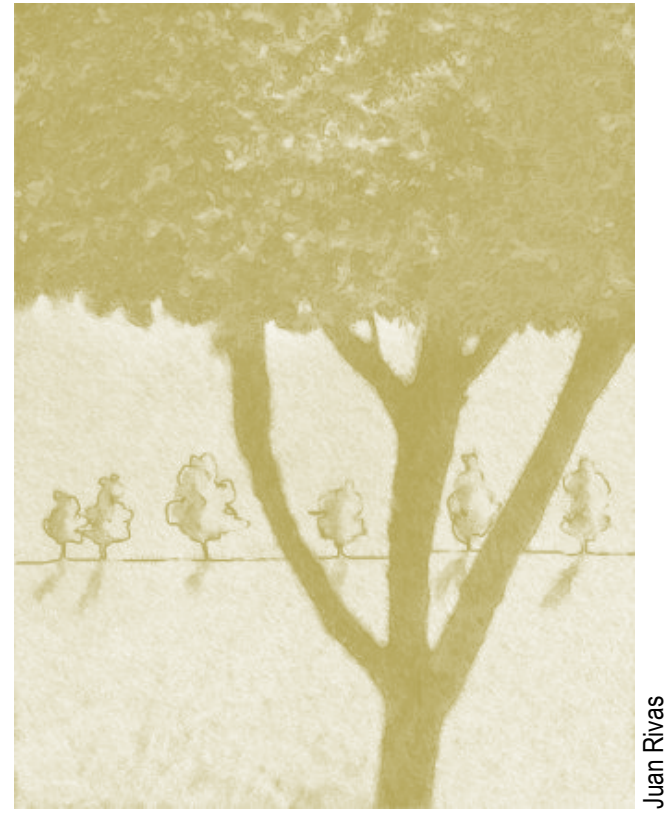

\section{EN ESTE FIN DE SIGLO}

Que el roce de su ala no me arrastre que pase de lado, obtuso

vago, loco, desquisiado.

Que no quede prendida en mi memoria la visión de su figura, que puedan mis ojos esquivar su mirada. Que olvide que existo en esta circunstancia en este país, en este fin de siglo en que lavo mi rostro en un cuenco vacío y reparo en la suerte que avisan las líneas de mis manos.

Que no vuelva a tocarme con su dedo de luz, que no anhele dejarme marcada que su aliento no caliente mi almohada.

Díganle sí que cuando el día muera venga en la noche a visitar mi cama y que cabalgue sobre mí sin verme el rostro sin decirme su nombre y que mañana como un ladrón se esconda.

Washington DC, 1998(Plaza de los Comunes, 2001) 


\section{Literatura}

\section{MATERNIDAD}

Mi ombligo es el centro del universo

las cosas giran alrededor mío

y camino envuelta en una burbuja de energía.

Los dioses me protegen,

- aún los que no conozco o no he sentido -

van a mi lado, danzan alrededor.

Lo apuntan mis ojos incoloros,

irradio luz.

No hay nada más sobre la tierra

que lo que guardo en mi interior.

La canasta de matrimonio de los indígenas americanos

ha venido a posar en el escenario redondo y tibio

de mi vientre.

Soy el centro,

la cruz, la seña

que asoma de noche en la oscuridad

de los perdidos.

Soy el sol y la tierra,

la lluvia, nieve pura que nos cubre.

Washington DC, 1994

(Plaza de los Comunes, 2001)

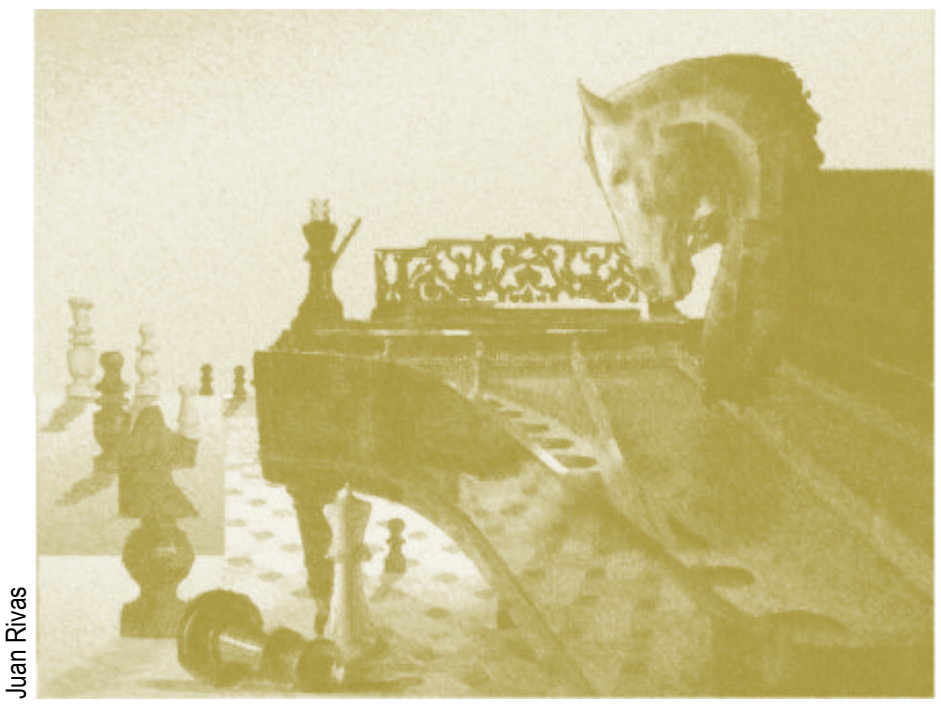

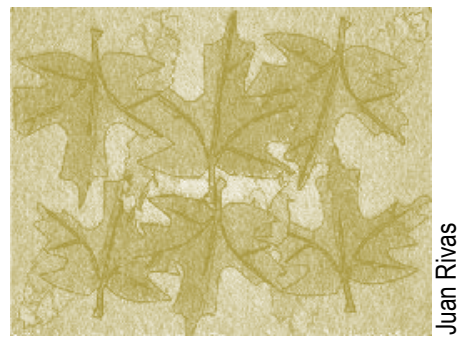

\section{MONÓLOGO}

En esta edad no temo a nada

el cuerpo no rinde más culto

a la belleza

ni el alma busca a tientas su origen.

A mis tres años

tengo la experiencia de una mujer

de setenta,

liberada de selvas y de cazadores

blancos

sin miedo a entrar en aguas

de verdes cocodrilos.

En esta edad

no temo a sentarme mal,

tengo las dos piernas abiertas

donde se divisa un hueco negro

marco de tu risa.

Tengo la energía para jugar con leones dar paseos lentos subida a un elefante, perezozo y tristón,

asida a su lomo ceniciento.

Agarro con mis manos las tormentas caben en un rincón las nubes

todo el hemisferio austral

en la sonrisa.

En un cuento de viejas

una enérgica niña

salta de una alta pared al vacío. 